\title{
Factor XIII activity mediates red blood cell retention in venous thrombi
}

\author{
Maria M. Aleman, ${ }^{1}$ James R. Byrnes, ${ }^{1}$ Jian-Guo Wang, ${ }^{1}$ Reginald Tran, ${ }^{2}$ Wilbur A. Lam, ${ }^{2}$ Jorge Di Paola, ${ }^{3}$ Nigel Mackman, ${ }^{4,5}$ \\ Jay L. Degen, ${ }^{6}$ Matthew J. Flick, ${ }^{6}$ and Alisa S. Wolberg ${ }^{1,4}$ \\ 'Department of Pathology and Laboratory Medicine, University of North Carolina at Chapel Hill, Chapel Hill, North Carolina, USA. ${ }^{2}$ Wallace H. Coulter Department of Biomedical Engineering, \\ Georgia Institute of Technology and Emory University, Atlanta, Georgia, USA. ${ }^{3}$ Department of Pediatrics and Human Medical Genetics and Genomics Program, University of Colorado, Denver, \\ Colorado, USA. ${ }^{4}$ McAllister Heart Institute and ${ }^{5}$ Department of Medicine, Division of Hematology/Oncology, University of North Carolina at Chapel Hill, Chapel Hill, North Carolina, USA. \\ ${ }^{6}$ Department of Pediatrics, Cincinnati Children's Hospital Medical Center, Cincinnati, Ohio, USA
}

\begin{abstract}
Venous thrombi, fibrin- and rbc-rich clots triggered by inflammation and blood stasis, underlie devastating, and sometimes fatal, occlusive events. During intravascular fibrin deposition, rbc are thought to become passively trapped in thrombi and therefore have not been considered a modifiable thrombus component. In the present study, we determined that activity of the transglutaminase factor XIII (FXIII) is critical for rbc retention within clots and directly affects thrombus size. Compared with WT mice, mice carrying a homozygous mutation in the fibrinogen $\gamma$ chain (Fib $\gamma^{390-396 A}$ ) had a striking $50 \%$ reduction in thrombus weight due to reduced rbc content. Fibrinogen from mice harboring the Fib $\gamma^{390-3964}$ mutation exhibited reduced binding to FXIII, and plasma from these mice exhibited delayed FXIII activation and fibrin crosslinking, indicating these residues mediate FXIII binding and activation. FXIII-deficient mice phenocopied mice carrying Fib $\gamma^{390-396 A}$ and produced smaller thrombi with fewer rbc than WT mice. Importantly, FXIII-deficient human clots also exhibited reduced rbc retention. The addition of FXIII to FXIII-deficient clots increased rbc retention, while inhibition of FXIII activity in normal blood reduced rbc retention and produced smaller clots. These findings establish the FXIII-fibrinogen axis as a central determinant in venous thrombogenesis and identify FXIII as a potential therapeutic target for limiting venous thrombosis.
\end{abstract}

\section{Introduction}

Venous thrombi are rbc-rich clots that afflict 1 million Americans annually. The prevailing paradigm suggests rbc are incorporated into venous thrombi via passive trapping during intravascular fibrin deposition (1). However, little is known about the mechanisms regulating this process, or how rbc incorporation into thrombi contributes to thrombus size or function.

The fibrin precursor, fibrinogen, is a plasma glycoprotein $\left(\mathrm{M}_{\mathrm{r}}\right.$ $340 \mathrm{kDa}$ ) consisting of $2 \mathrm{~A} \alpha$-chains, $2 \mathrm{~B} \beta$-chains, and $2 \gamma$-chains, which circulate at 2 to $5 \mathrm{mg} / \mathrm{ml}$. During coagulation, fibrinogen is cleaved by thrombin and polymerized into an insoluble, but highly extensible and elastic (2), network. The transglutaminase factor XIII(a) (FXIIIa) produces $\varepsilon-\mathrm{N}$-( $\gamma$-glutamyl)-lysine crosslinks between residues in the $\gamma$ - and $\alpha$-chains that stabilize the fibrin network and are essential for clot mechanical stability and protection against premature dissolution during wound healing.

The $\mathrm{C}$ terminus of the fibrinogen $\gamma$-chain interacts with a myriad of soluble and cell-associated proteins (3). In particular, previous studies have shown that fibrinogen residues $\gamma 390-395$, located imme-

Note regarding evaluation of this manuscript: Manuscripts authored by scientists associated with Duke University, The University of North Carolina at Chapel Hill, Duke-NUS, and the Sanford-Burnham Medical Research Institute are handled not by members of the editorial board but rather by the science editors, who consult with selected external editors and reviewers.

Conflict of interest: The authors have declared that no conflict of interest exists. Submitted: January 27, 2014; Accepted: May 21, 2014.

Reference information: J Clin Invest. 2014;124(8):3590-3600. doi:10.1172/JCI75386. diately upstream of the FXIIIa crosslinking sites on the fibrin(ogen) $\gamma$-chains, mediate interactions with the CD11b subunit of CD11b/ CD18 (Mac-1). Mice with a mutation of this region (Fib $\left.\gamma^{390-396 A}\right)$ have normal fibrinogen levels and exhibit normal fibrin polymerization and platelet aggregation (4). However, Fib ${ }^{390-396 A}$ mice have defective clearance of Staphylococcus aureus (4) and are protected against autoinflammatory disorders (5-9). These effects are thought to stem from the lack of fibrin-driven leukocyte responses during inflammation.

The protransglutaminase FXIII consists of 2 catalytic subunits (FXIII-A) and 2 noncatalytic subunits (FXIII-B) in a noncovalent, heterotetramer (FXIII- $\mathrm{A}_{2} \mathrm{~B}_{2}, \mathrm{M}_{\mathrm{r}}, 325 \mathrm{kDa}$ ). FXIII- $\mathrm{A}_{2} \mathrm{~B}_{2}$ is activated by thrombin-catalyzed release of a 37 -amino acid activation peptide from the $\mathrm{N}$ terminus of the FXIII-A subunits $(10,11)$ and calcium-mediated dissociation of FXIII-B subunits from FXIII-A, yielding activated FXIII-A (FXIII-A $_{2}^{*}$ ) (12-14). Essentially all FXIII- $\mathrm{A}_{2} \mathrm{~B}_{2}$ in plasma $(70 \mathrm{nM})$ circulates in complex with fibrinogen $(15,16)$; however, the residues in fibrinogen that mediate FXIII- $\mathrm{A}_{2} \mathrm{~B}_{2}$ binding have not been defined.

Herein, we analyzed the role of fibrinogen residues $\gamma 390-396$ in venous thrombosis. Our data indicate fibrinogen residues $\gamma 390-$ 396 mediate FXIII- $\mathrm{A}_{2} \mathrm{~B}_{2}$ binding and activation and reveal a critical role for FXIIIa activity in venous thrombosis. These findings redefine the paradigm describing mechanisms regulating the cellular composition of venous thrombi.

\section{Results}

Thrombi from Fib $\gamma^{390-396 A}$ mice are smaller and have reduced rbc content compared with thrombi from WT mice. To determine the 

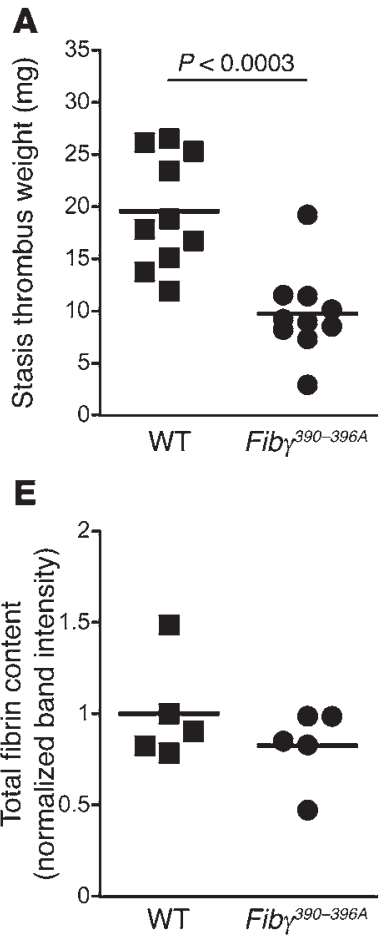

B

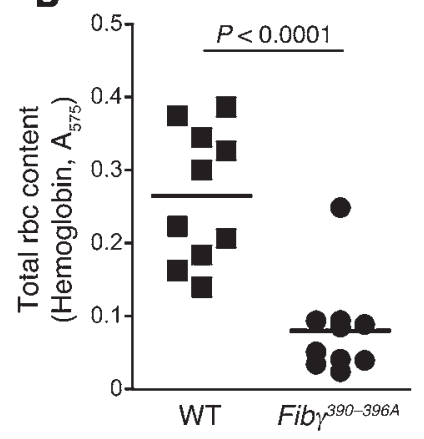

$\mathbf{F}$

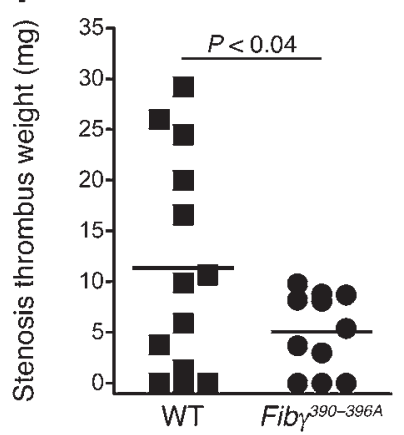

C

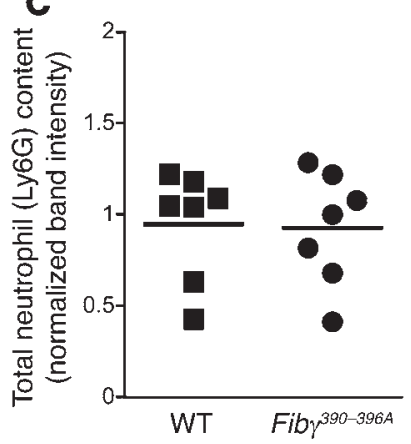

G

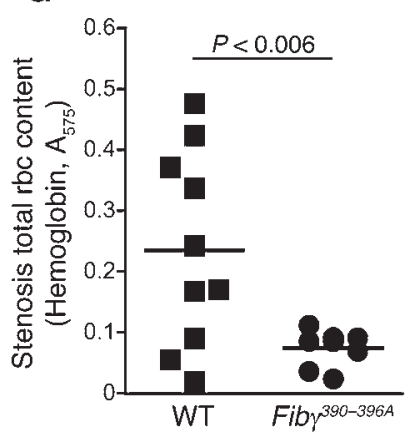

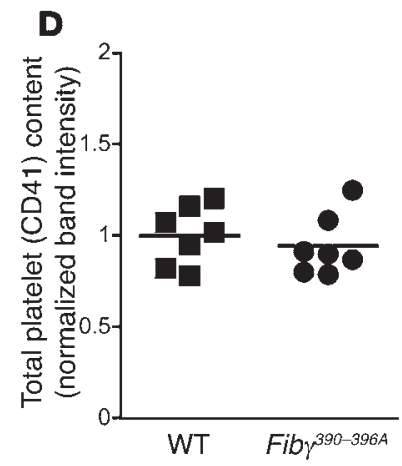

Figure 1. Compared with thrombi from WT mice, thrombi from Fiby ${ }^{390-396 A}$ mice are smaller and have reduced rbc content. (A) Thrombus weights 1 day after ligation (stasis model). (B) Total rbc content of stasis thrombus lysates, measured as hemoglobin absorbance at 575 nm. (C) Total neutrophil content of thrombus lysates, measured by Ly6C antigen. (D) Total platelet content of thrombus lysates, measured by CD41 antigen. (E) Total fibrin ( $\beta$-chain) antigen of thrombus lysates. (F) Thrombus weights 1 day after ligation (stenosis model). (G) Total rbc content of stenosis thrombus lysates, measured as hemoglobin absorbance at $575 \mathrm{~nm}$. Each dot represents an individual mouse. Lines represent means.

role of fibrinogen residues $\gamma 390-396$ in venous thrombosis, we first used the inferior vena cava (IVC) ligation (stasis) thrombosis model that produces thrombi independent of leukocyte tissue factor activity $(17,18)$. Surprisingly, thrombi from Fibr ${ }^{390-396 \mathrm{~A}}$ mice were $50 \%$ smaller than thrombi from WT mice 1 day after ligation (Figure 1A). Reduced thrombus weight was not due to reduced procoagulant activity; plasma from WT and Fib $\gamma^{390-396 A}$ mice had similar thrombin generation in vitro (Supplemental Figure 1A; supplemental material available online with this article; doi:10.1172/JCI75386DS1), and circulating thrombin-antithrombin (TAT) complex levels were similar in WT and Fib $\gamma^{390-396 A}$ mice following thrombus formation in vivo (Supplemental Figure 1B). Strikingly, however, thrombus lysates from Fib $\gamma^{390-396 A}$ mice had significantly reduced hemoglobin (absorbance at $575 \mathrm{~nm}$, Figure 1B) and reduced erythrocyte spectrin $\alpha 1$ content (Supplemental Figure 2), indicating that Fib $\gamma^{390-396 A}$ thrombi contained fewer rbc than WT thrombi. Furthermore, for both WT and Fib $\gamma^{390-396 A}$ thrombi, thrombus rbc content correlated positively and significantly with thrombus weight $\left(R^{2}=0.80, P<0.0001\right)$, indicating rbc content is the major determinant of thrombus size. Western blots of thrombus lysates showed thrombi from WT and Fib $\gamma^{390-396 A}$ mice did not differ in neutrophil, platelet, or fibrin content (Figure 1, C-E). Results in a second venous thrombosis model that involves stenosis rather than complete ligation (19, 20) were similar; despite the typical variability in clot sizes in this model, Fib $\gamma^{390-396 A}$ mice displayed reduced thrombus weights and reduced rbc presence compared with WT mice (Figure 1, F and G). Together, these data suggest Fib $\gamma^{390-396 A}$ mice produce smaller venous thrombi because of reduced rbc incorporation and/or retention during thrombogenesis.

rbc are extruded from Fib ${ }^{390-396 \mathrm{~A}}$ clots during clot retraction. To test the hypothesis that reduced rbc content of Fib $\gamma^{390-396 A}$ thrombi was due to a failure to retain rbc during clot formation and retraction, we developed an ex vivo whole blood assay in which whole blood is clotted with tissue factor and $\mathrm{CaCl}_{2}$. In this assay, clot formation is immediately followed by platelet-mediated clot retraction, which is complete within 60 to 90 minutes. Initially, clotting proceeded similarly for both WT and Fib $\gamma^{390-396 \mathrm{~A}}$ blood. However, compared with WT clots, fully retracted Fib $\gamma^{390-396 \mathrm{~A}}$ clots exhibited reduced rbc retention (Figure 2, A and B), increased clot retraction (Figure 2A), and reduced clot weight (Figure $2 \mathrm{C}$ ). Consistent with observations in vivo, clot rbc content correlated positively and significantly with clot weight $\left(R^{2}=0.62\right.$, $P<0.0003)$. Loss of rbc from clots was not due to diminished platelet-mediated contraction because, in the absence of rbc, clot retraction was identical in WT and Fib ${ }^{390-396 A}$ platelet-rich plasma (PRP) (Figure 2, D and E). Loss of rbc was also not due to deficient interactions between fibrin(ogen) and CD11b (the molecular interaction previously shown to be deficient in Fib $\gamma^{390-396 \mathrm{~A}}$ mice; ref. 4) because whole blood from $C D 11 b^{-/-}$mice (21) exhibited normal rbc retention during clot retraction (Supplemental Figure 3A). rbc extrusion was not due to a defect in rbc function; when we separately prepared PRP and washed rbc from WT and Fib $\gamma^{390-396 A}$ mice and mixed WT rbc with Fib $\gamma^{390-396 A}$ PRP and vice versa, rbc extrusion remained associated with the PRP from Fib $\gamma^{390-396 A}$ mice (Figure 2F). When whole blood from WT and 
A

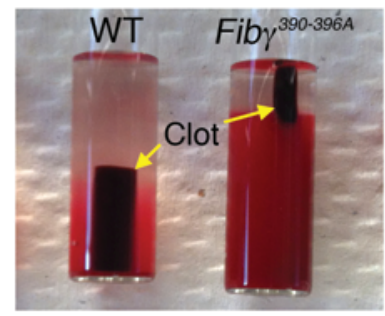

D

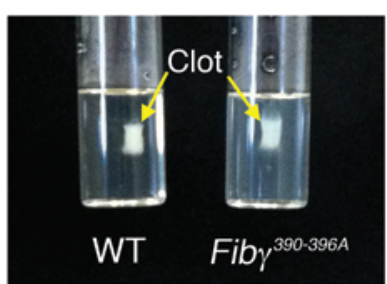

B

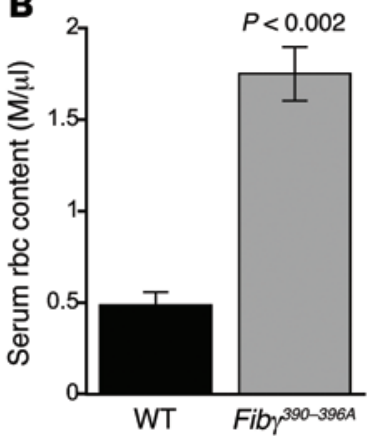

E

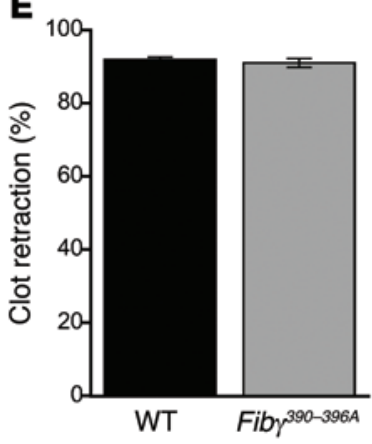

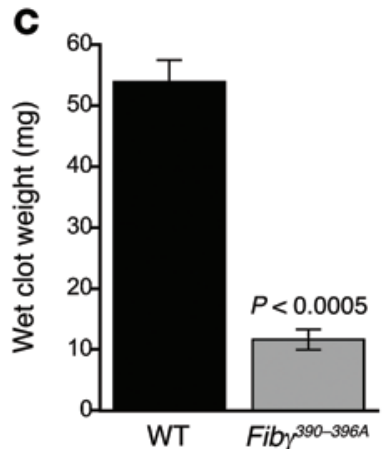

$\mathbf{F}$

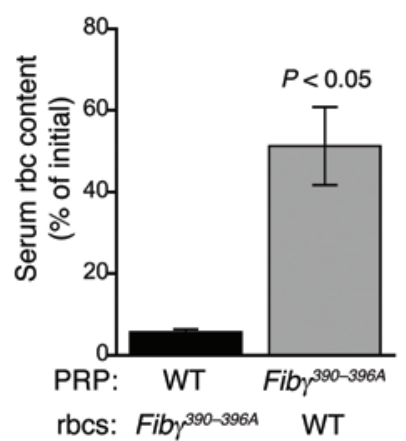

Figure 2. rbc are extruded from Fib $\gamma^{390-3964}$ clots during clot retraction, resulting in decreased clot weight. After clot formation, platelet contractile force retracts clots away from siliconized tube walls, leaving the clots surrounded by serum. (A) Image of fully retracted WT and Fib $\gamma^{390-396 A}$ clots 90 minutes after initiation of clot formation by tissue factor and $\mathrm{CaCl}_{2}$. (B) Number of rbc present in the serum following clot retraction $(n=3)$. (C) Wet clot weights following clot retraction $(n=3)$. (D) Image of fully retracted PRP clots 90 minutes after initiation of clot formation. (E) Percentage retraction of PRP clots $(n=3)$. (F) Serum rbc content of retracted clots containing WT PRP with Fib $\gamma^{390-396 A}$ rbc and vice versa $(n=3)$. Data represent mean \pm SEM.

Fib $\gamma^{390-396 A}$ mice was mixed in equal parts, retracted clot weights were intermediate between WT and Fib ${ }^{390-396 A}$ clots (Supplemental Figure 3B).

Since rbc bind to platelet $\alpha_{\mathrm{II}} \beta_{3}(22,23)$, we tested the hypothesis that rbc-platelet interactions mediated rbc retention in clots. We combined platelet-free plasma (PFP) from WT and Fib $\gamma^{390-396 A}$ mice with washed rbc from WT mice, triggered clotting with tissue factor and $\mathrm{CaCl}_{2}$, and then measured rbc released from the fully formed clots. Under these conditions, Fib $\gamma^{390-396 \mathrm{~A}}$ clots released more rbc than WT clots $(3.6 \% \pm 0.6 \%$ versus $1.3 \% \pm 0.1 \%$ of initial, $P<0.02, n=5)$. However, compared with clots formed in the presence of platelets (Figure 2F), both WT and Fib $\gamma^{390-396 A}$ platelet-free clots released significantly ( $>10$-fold) fewer rbc. These data show that platelet-mediated clot retraction promotes extrusion of rbc from $F i b \gamma^{390-396 A}$ clots and that platelets are not required to retain rbc in either WT or Fib $\gamma^{390-396 A}$ plasma clots. Together, these findings show defective retention of rbc in clots made from blood containing the mutant $\left(F i b \gamma^{390-396 A}\right)$ fibrinogen.

Fibrinogen residues $\gamma 390-396$ do not bind to rbc. To determine whether fibrinogen residues $\gamma 390-396$ make up a specific motif that mediates rbc binding, we used a microfluidic-based adhesion assay to measure binding of rbc to purified, immobilized WT and Fib $\gamma^{390-396 A}$ fibrin(ogen). Whereas rbc did not adhere to BSA-coated microchannels, rbc adhered to both WT and Fib $\gamma^{390-396 A}$ purified fibrin(ogen) and remained bound even when subject to high shear wash rates (Figure 3A). Importantly, there were no differences in the percentage of rbc that remained bound to WT and Fib $\gamma^{390-396 A}$ fibrin(ogen) ( $P=1.0$, Figure 3B), indicating residues $\gamma 390-396$ do not mediate a direct interaction between $\mathrm{rbc}$ and fibrin(ogen).

Fibrinogen isolated from Fib ${ }^{390-396 A}$ mice has reduced binding to FXIII. Since our results associated defective thrombus rbc retention with the mutated fibrin(ogen), we isolated fibrinogen from WT and Fib $\gamma^{390-396 A}$ plasma by glycine precipitation and used SDS-PAGE for further analysis. Surprisingly, we identified 2 protein bands $\left(\mathrm{M}_{\mathrm{r}} \sim 83\right.$ and $\sim 76 \mathrm{kDa}$ ) present with equal staining intensity that coprecipitated with purified WT, but not Fib $\gamma^{390-396 A}$, fibrinogen (Figure 4A). Mass spectrometry identified these bands as the A and B subunits of FXIII- $\mathrm{A}_{2} \mathrm{~B}_{2}$, and Western blotting with an anti-FXIII-A subunit antibody confirmed the presence of FXIII in purified WT but not purified Fib $\gamma^{390-396 A}$ fibrinogen (Figure 4B). Since Fib $\gamma^{390-396 A}$ mice have normal levels of circulating FXIII in plasma (Figure 4C and Supplemental Figure 4) and since FXIII binding to WT fibrinogen is well established, these data suggest plasma FXIII- $\mathrm{A}_{2} \mathrm{~B}_{2}$ has reduced binding affinity for fibrinogen from Fib $\gamma^{390-396 A}$ mice. Binding assays evaluating FXIII- $\mathrm{A}_{2} \mathrm{~B}_{2}$ binding to adherent fibrin(ogen) support this hypothesis: compared with WT fibrin(ogen), FXIII- $\mathrm{A}_{2} \mathrm{~B}_{2}-$ bound Fib $\gamma^{390-396 A}$ fibrin(ogen) with approximately 6-fold weaker affinity (16 \pm 4 versus $90 \pm 24 \mathrm{nM}$, respectively, Figure 4D) with no evidence of cooperative binding to either WT or Fib $\gamma^{390-396 \mathrm{~A}}$ fibrin(ogen) (Hill coefficients 1 ). These data suggest fibrinogen $\gamma$-chain residues 390-396 support interactions with FXIII- $\mathrm{A}_{2} \mathrm{~B}_{2}$.

Plasma from Fib $\gamma^{390-396 A}$ mice exhibits delayed FXIII activation and delayed fibrin crosslinking. The initial characterization of Fib $\gamma^{390-396 A}$ mice showed that purified fibrinogen from these mice 
A
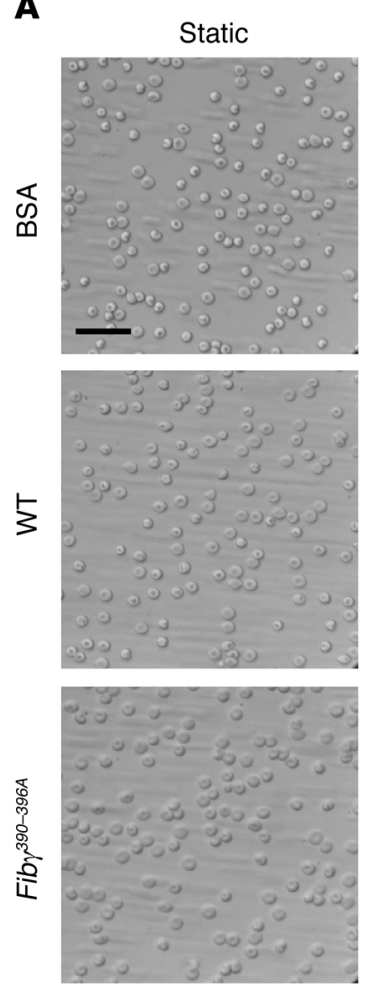
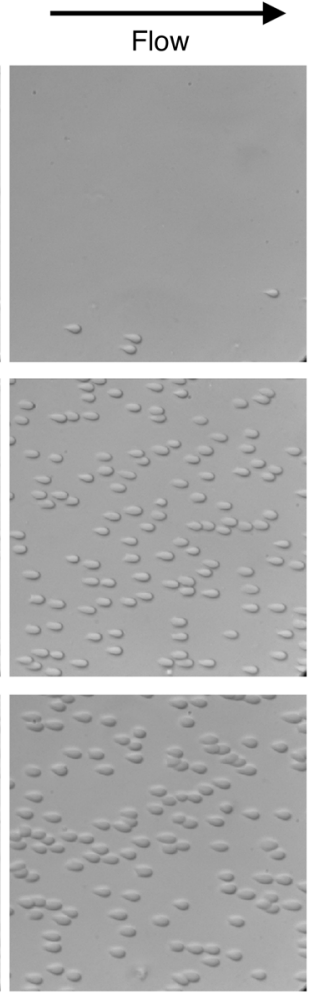

can be crosslinked by activated FXIII (4). However, those experiments were performed with low fibrinogen $(0.25 \mathrm{mg} / \mathrm{ml}, 10$-fold lower than plasma levels) and high human FXIII- $\mathrm{A}_{2} \mathrm{~B}_{2}(470 \mathrm{nM}$, 6.7-fold higher than plasma levels). These conditions would have masked reduced binding affinity and could explain why this difference was not detected. Therefore, we measured the kinetics of FXIII activation and fibrin crosslinking during tissue factor-initiated plasma clotting. Compared with WT, plasma from Fib ${ }^{390-396 \mathrm{~A}}$ mice exhibited approximately 5 -fold slower conversion of FXIII$\mathrm{A}_{2} \mathrm{~B}_{2}$ to FXIII- $\mathrm{A}_{2}^{*}\left(58.3 \pm 19.2\right.$ versus $12.2 \pm 2.5 \mathrm{AU} / \mathrm{min}\left[\times 10^{-3}\right]$, $P<0.04$, Figure 5, A and B). Since association of FXIII- $\mathrm{A}_{2} \mathrm{~B}_{2}$ with fibrin(ogen) accelerates its activation, these data are consistent with reduced affinity between FXIII- $\mathrm{A}_{2} \mathrm{~B}_{2}$ and Fib $\gamma^{390-3964}$ fibrinogen. Accordingly, compared with WT, plasma clots from Fib ${ }^{390-396 \mathrm{~A}}$ mice exhibited an approximately 6-fold reduced rate of formation of both $\gamma-\gamma$ dimers $(P<0.0005$, Figure $5, C$ and $D)$ and high MW crosslinked species $(P<0.004$, Figure $5, \mathrm{C}$ and $\mathrm{E})$, consistent with the delay in FXIII- $\mathrm{A}_{2}^{*}$ generation. Notably, the time course of fibrin crosslinking in these experiments mirrors the time frame during which $\mathrm{rbc}$ were extruded during in vitro clot retraction. Together, these data demonstrate a defect in FXIII- $\mathrm{A}_{2} \mathrm{~B}_{2}$ activation and activity in Fib $\gamma^{390-396 A}$ mice and suggest decreased FXIII activity permits rbc extrusion during clot retraction, resulting in smaller thrombi.

FXIII-deficient mice produce smaller thrombi with reduced rbc content. To determine the effect of FXIII on thrombus formation in vivo, we performed the IVC ligation stasis model on mice deficient in the FXIII catalytic A-subunit $\left(F 13 a^{-/}\right)(24)$. Similar to that seen in Fib $\gamma^{390-396 A}$ mice (Figure 1A), thrombi from $F 13 a^{-/}$mice had significantly reduced weights compared with $F 13 a^{+/+}$controls (Figure 6A). Unlike in Fib $\gamma^{390-396 A}$ mice, thrombi from $F 13 a^{-/}$mice showed reduced neutrophil and platelet content compared with $\mathrm{F} 3 \mathrm{a}^{+/+}$con-

\section{B}

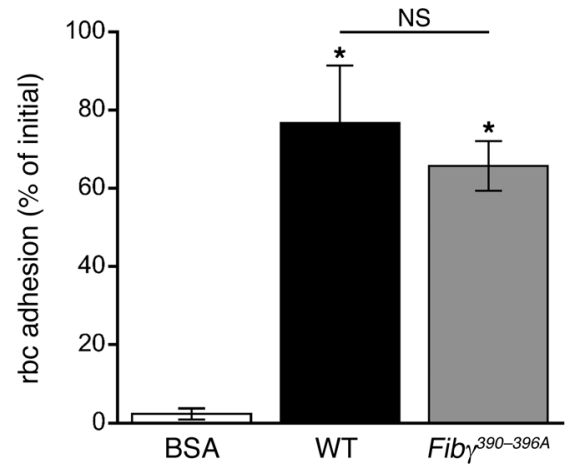

Figure 3. rbc adhere to fibrin(ogen) from WT and Fib $\gamma^{390-396 A}$ mice. (A) Adherence of rbc to BSA, WT fibrin(ogen), or Fib $\gamma^{390-396 A}$ fibrin(ogen) before and after application of flow with a shear rate of $1000 \mathrm{~s}^{-1}$. Scale bar: $30 \mu \mathrm{m}$. (B) Quantitation of rbc adhesion after application of flow. Data represent mean $\pm \operatorname{SEM}(n=3) .{ }^{*} P<0.009$, versus BSA by ANOVA.

trols (Figure 6, B and C), suggesting a role for FXIII in general cell retention in thrombi. However, thrombi from $\mathrm{F}_{13 \mathrm{a}^{-/} \text {mice showed }}$ normal fibrin content (Figure 6D), consistent with the observation that thrombus formation in the stasis model is independent of leukocyte tissue factor activity $(17,18)$. Importantly, lysates of thrombi from $\mathrm{F}_{13 a^{-/}}$mice revealed significantly reduced thrombus rbc content (hemoglobin [Figure 6E] and erythrocyte spectrin $\alpha 1$ [Supplemental Figure 5]) compared with $F 13 a^{+/+}$controls. Although some $\mathrm{F} 13 \mathrm{a}^{+/+}$controls also produced small thrombi, the rbc density of these smaller thrombi was similar to that of larger thrombi from $F 13 a^{+/+}$controls (Supplemental Figure 6). Notably, the thrombus rbc content from both $F 13 a^{-/}$and $F 13 a^{+/+}$mice correlated positively and significantly with thrombus weight $\left(R^{2}=0.95, P<0.0001\right)$.

To determine the role of FXIIIa activity in rbc retention during clotting, we measured rbc retention during clot retraction in whole blood from $\mathrm{F} 13 \mathrm{a}^{-/}$mice and $\mathrm{F} 13 \mathrm{a}^{+/+}$controls. Whole blood from $\mathrm{F} 13 \mathrm{a}^{-/}$mice exhibited reduced rbc retention during clot retraction (Figure 6F), phenocopying that seen in Fiby $\gamma^{390-396 \mathrm{~A}}$ clot retraction (Figure 6G and Figure 2, A-C). Together, these data indicate FXIII activity dictates rbc retention in venous thrombi.

FXIII determines rbc content and size of clots formed in human whole blood. "Excessive red cell fallout" during clot retraction was previously reported in a study of a family with congenital FXIII deficiency (25); however, the finding was not pursued. To determine whether plasma FXIII activity is required for rbc retention in human clots, we reconstituted plasma from a FXIII-deficient human patient with washed platelets and rbc from healthy individuals. Reactions were performed in the absence and presence of exogenous plasma-derived FXIII- $\mathrm{A}_{2} \mathrm{~B}_{2}$ (Fibrogammin-P) added at doses recommended for prophylaxis $(10 \mathrm{IU} / \mathrm{kg}, 0.15 \mathrm{IU} / \mathrm{ml})$ and surgery $(33 \mathrm{IU} / \mathrm{kg}, 0.5 \mathrm{IU} / \mathrm{ml})$ and a dose to return FXIII- $\mathrm{A}_{2} \mathrm{~B}_{2}$ levels to nor- 
A
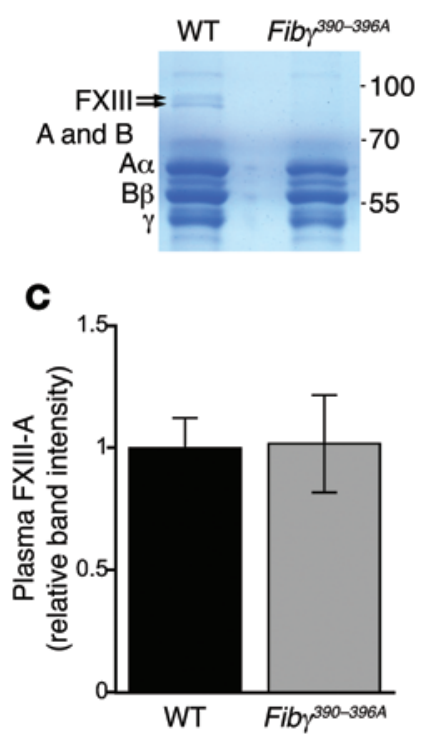

B

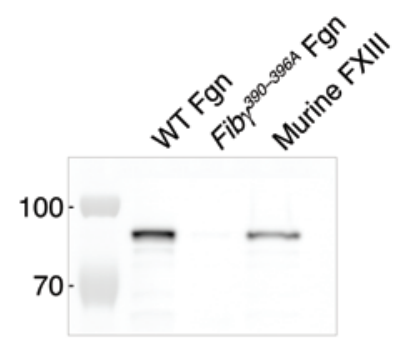

D

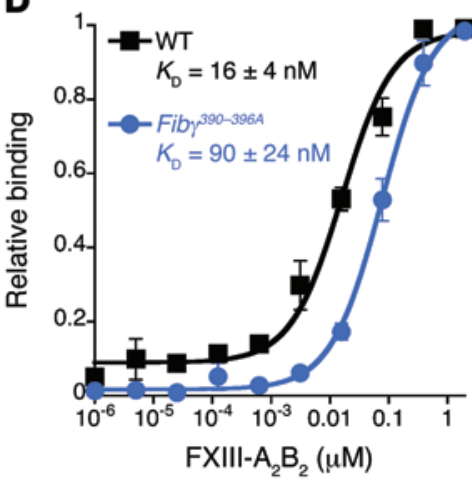

Figure 4. FXIII-A $\mathbf{B}_{2}$ does not coprecipitate with Fib $\gamma^{390-3964}$ fibrinogen. (A) Blue silverstained 10\% Tris-glycine gel containing purified fibrinogens from WT and Fib $\gamma^{390-396 A}$ mice. Bands indicated with arrows were analyzed by mass spectrometry. (B) Western blot detection of FXIII-A subunit in purified fibrinogen (Fgn) samples shown in $\mathbf{A}$ and commercial murine FXIII as a positive control. (C) Relative level of FXIII-A in WT and Fibr ${ }^{390-396 A}$ plasmas. Data represent means \pm SEM $(n=4)$. (D) Relative binding curves of plasma-purified FXIII- $\mathrm{A}_{2} \mathrm{~B}_{2}$ (Fibrogammin-P) to purified fibrinogen from WT or Fib $\gamma^{390-396 \mathrm{~A}}$ mice. Data represent normalized means $\pm \operatorname{SEM}(n=4)$.

mal (67 IU/kg, $1 \mathrm{IU} / \mathrm{ml})$. FXIII-deficient clots exhibited reduced rbc retention following clot retraction (Figure 7A). Notably, rbc retention in FXIII-deficient human plasma was corrected by addition of FXIII- $\mathrm{A}_{2} \mathrm{~B}_{2}$ in a dose-dependent manner (Figure 7A).

Finally, to determine whether blocking FXIII activity can reduce rbc retention and clot size, we treated normal human whole blood with the irreversible FXIII active site inhibitor T101 and induced clot formation and retraction. Following clot retraction, baseline levels of rbc present in serum exhibited interindividual variability $(44.7 \% \mathrm{CV})$; however, for all donors, T101 produced a dose-dependent increase in serum rbc content $\left(\mathrm{IC}_{50} 0.46 \pm 0.07\right.$ $\mu \mathrm{M}$, Figure $7 \mathrm{~B})$, resulting in a $46 \% \pm 8 \%$ reduction in clot size. These data show FXIII activity is a major determinant of clot rbc content and clot size in mice and humans.

\section{Discussion}

The discovery that FXIII(a) mediates rbc retention in venous thrombi redefines the pathophysiologic process that culminates in venous thrombus formation and reveals what may be a novel therapeutic target to reduce venous thrombosis. We found that venous thrombus size is primarily determined by rbc content, suggesting venous thrombosis can be reduced by limiting rbc incorporation. We demonstrated that rbc retention in thrombi requires FXIII activity. This finding indicates that rbc are not simply ensnared by the fibrin meshwork during thrombus formation, but that once present, they must be actively retained within the thrombus by this enzymatic activity during clot retraction. Our data reveal critical

residues in the fibrinogen $\gamma$-chain that mediate FXIII zymogen binding to fibrinogen and, consequently, FXIII- $\mathrm{A}_{2} \mathrm{~B}_{2}$ activation and activity. To our knowledge, these findings are the first to implicate these residues in fibrinogen's FXIII carrier function. Finally, our findings with Fib $\gamma^{390-396 A}$ mice delineate the essential, synchronized events governing fibrin formation, crosslinking, and platelet-mediated clot retraction during venous thrombogenesis.

Venous thromboembolism and atrial fibrillationassociated thrombosis affect millions of Americans each year $(26,27)$. Moreover, increased venous thrombus burden (size) is associated with increased morbidity and mortality, and decreased clot burden is associated with lower risk of recurrence (28). Consequently, an agent that can prevent or reduce thrombus size may be an attractive thromboprophylactic drug. Since FXIIIa inhibition decreases clot size, mechanical stability, and resistance to fibrinolysis, this approach would be expected to both decrease thrombosis and accelerate clot dissolution. Moreover, since in vitro studies suggest $\mathrm{rbc}$ packing reduces diffusion within retracted clots (29), decreasing thrombus rbc content may also increase diffusion of thrombolytics into thrombi, making FXIIIa inhibition a multipronged antithrombotic approach. The FXIIIa inhibitor we used in vitro is similar to another thioimidazolium derivative (L-722.151) that was previously evaluated in arterial thrombolysis models in rabbits (30) and dogs (31). Although L-722.151 accelerates thrombolysis, its short half-life $(\sim 5$ minutes) limited its continued development. Our data warrant renewed interest in the development of FXIIIa inhibitors for the treatment and prevention of thrombosis. In particular, although total FXIII deficiency is associated with bleeding (32), Fiby ${ }^{390-396 \mathrm{~A}}$ mice do not exhibit spontaneous bleeding or hemostatic defects, fully tolerate the abdominal surgery involved in the IVC thrombosis models, and exhibit normal wound healing at the incision site. Thus, blocking the interaction between FXIII- $\mathrm{A}_{2} \mathrm{~B}_{2}$ and fibrinogen or delaying FXIII activation are potentially safe approaches to reducing venous thrombosis.

Our findings also have important clinical implications for managing hemostasis. While congenital FXIII deficiency is rare, acquired FXIII deficiency from surgical blood loss or inflammatory disease is more common but underdiagnosed due to the relative insensitivity of standard tests. However, mounting evidence suggests patients with "mild" FXIII deficiency due to heterozygosity or surgery have increased risk of bleeding (33). Consequently, the plasma level of FXIII required to maintain hemostasis in these patients is controversial. Our finding that FXIII mediates clot composition in a dose-dependent manner across the FXIII reference range suggests that $1 \mathrm{U} / \mathrm{ml}$ FXIII levels are required to achieve "normal" FXIII function and that even mildly reduced levels of FXIII can result in the formation of abnormal clots. Thus, maintaining higher concentrations of FXIII may decrease bleeding and improve wound healing in patients with congenital or acquired FXIII deficiency.

Essentially all FXIII- $\mathrm{A}_{2} \mathrm{~B}_{2}$ circulates bound to fibrinogen (15), and following activation, FXIII- $\mathrm{A}_{2}{ }^{*}$ crosslinks residues be- 
A

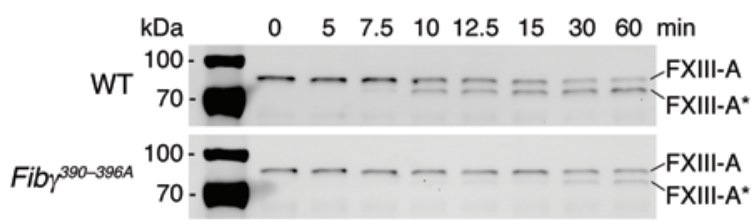

C

WT

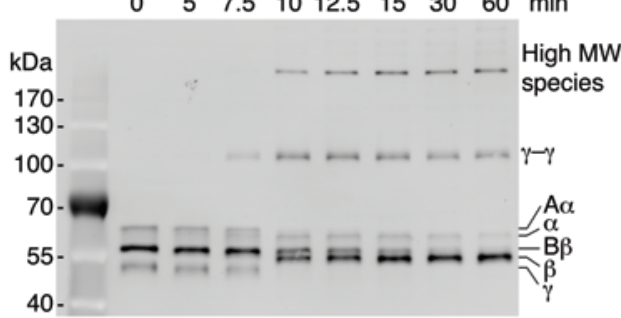

Fibr $\gamma^{390-3964}$

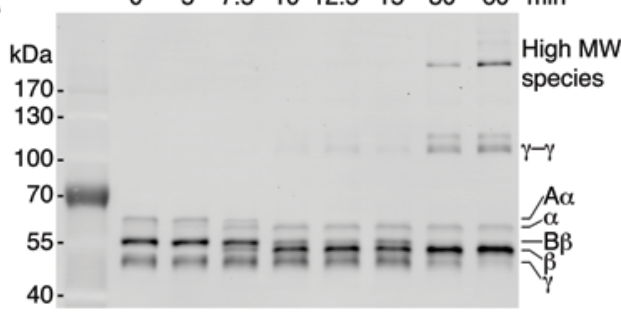

B

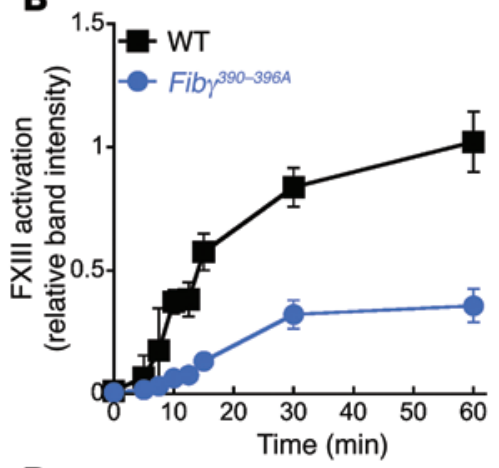

D
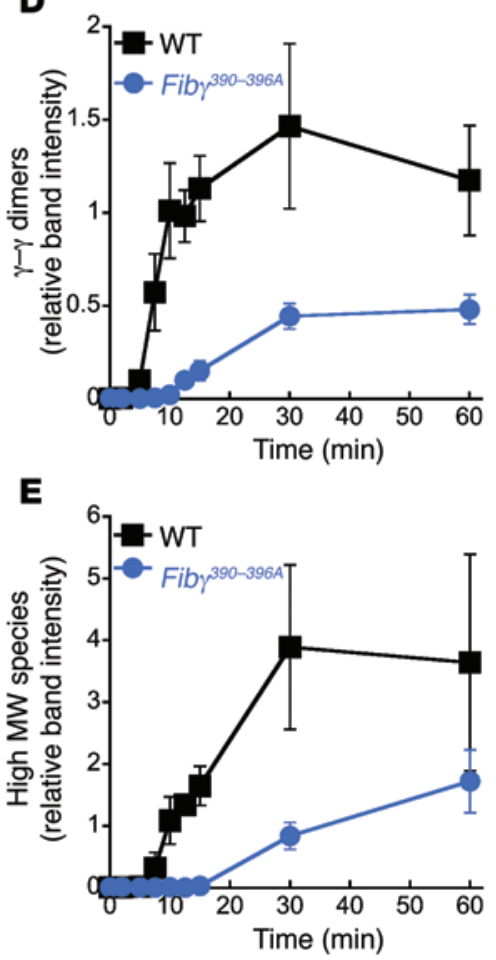

Figure 5. Compared with WT, plasma from Fib ${ }^{390-396 A}$ mice exhibits delayed FXIII activation and, consequently, delayed fibrin crosslinking during tissue factor-initiated coagulation. (A) Representative Western blots for FXIII-A during time course of tissue factor-initiated clotting in WT and Fib $\gamma^{390-396 A}$ plasma. Activated FXIII (FXIII-A*) appears over time as a lower MW band. (B) Quantitation of FXIII-A* appearance over time in blots from A. Data represent mean \pm SEM $(n=5)$. (C) Representative Western blots for fibrin(ogen) during time course of tissue factor-initiated clotting in WT and Fib $\gamma^{390-396 A}$ plasma showing $\gamma-\gamma$ dimer and high MW crosslinked species ( $\alpha-\alpha$ and $\alpha-\gamma$ polymers). (D) Quantitation of $\gamma-\gamma$ dimer formation over time in Western blots. (E) Quantitation of high MW crosslinked species over time in Western blots. Data represent mean $\pm \operatorname{SEM}(n=6)$.

tween both the $\gamma$ - and $\alpha$-chains of fibrinogen. Smith et al. recently showed high-affinity binding of FXIII- $\mathrm{A}_{2} \mathrm{~B}_{2}$ to a peptide containing amino acid residues $371-425$ of the fibrinogen $\alpha \mathrm{C}$ domain (34). However, since fibrinogen $\gamma$-chains are crosslinked prior to the $\alpha$-chains, residues on the fibrinogen $\gamma$-chain would more efficiently fulfill the carrier function for FXIII- $\mathrm{A}_{2} \mathrm{~B}_{2}$, with interactions between FXIII- $\mathrm{A}_{2} \mathrm{~B}_{2} /$ FXIII- $\mathrm{A}_{2}{ }^{*}$ and the $\alpha \mathrm{C}$ region arising after initial interactions between FXIII- $\mathrm{A}_{2} \mathrm{~B}_{2}$ and the $\gamma$-chain. Although previous studies suggested FXIII- $A_{2} B_{2}$ binds preferentially to a minor species of circulating fibrinogen containing an alternatively spliced C-terminal $\gamma$-chain (termed $\gamma^{\prime}$ ) (35), later studies demonstrated FXIII- $\mathrm{A}_{2} \mathrm{~B}_{2}$ binds similarly to $\gamma$ - and $\gamma^{\prime}$-containing recombinant fibrinogens (36). Our data indicate that mutations within fibrinogen residues $8390-396$ decrease the coprecipitation of FXIII- $\mathrm{A}_{2} \mathrm{~B}_{2}$ with plasma fibrinogen and disrupt the inter- action between FXIII- $\mathrm{A}_{2} \mathrm{~B}_{2}$ and adherent fibrin(ogen), suggesting these residues mediate this carrier function and/or positioning of FXIII prior to crosslinking or cause a conformational change in fibrin(ogen) that reduces FXIII binding. Given that the $\gamma$-chain residues crosslinked by FXIII are immediately $\mathrm{C}$-terminal to residues $\gamma 390-396$, localization of FXIII- $\mathrm{A}_{2} \mathrm{~B}_{2}$ at these residues would conveniently position FXIIIa for rapid crosslinking following its activation. Subsequent contributions from the $\alpha \mathrm{C}$ domain would facilitate crosslinking of $\alpha$-chain residues following formation of $\gamma-\gamma$ dimers. Thus, one hypothesis consistent with these data is that the FXIII- $\mathrm{A}_{2} \mathrm{~B}_{2}$ binding site is a composite between residues in the $A \alpha$ - and $\gamma$-chains and that disrupting either site reduces binding. Alternately, FXIII may be "handed off" between the fibrinogen $\gamma$-chain and the $\alpha \mathrm{C}$ domain during its activation and activity. Further analysis of FXIII- $\mathrm{A}_{2} \mathrm{~B}_{2}$ and FXIII- $\mathrm{A}_{2}{ }^{*}$ inter- 
A
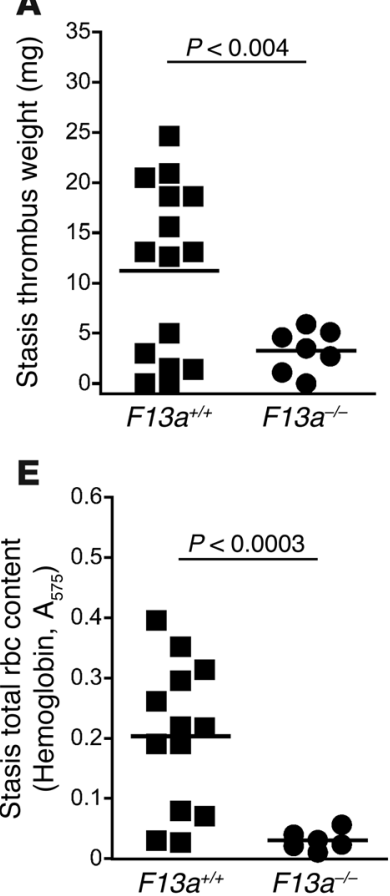

B

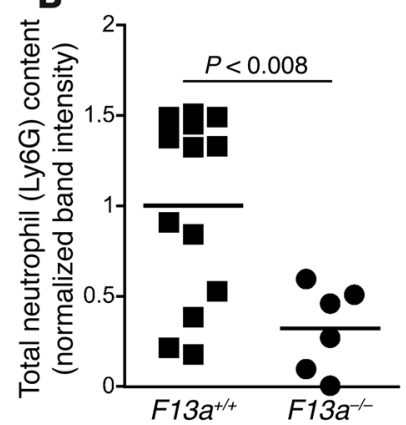

$\mathbf{F}$

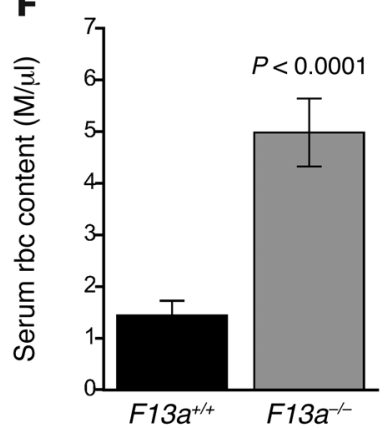

C

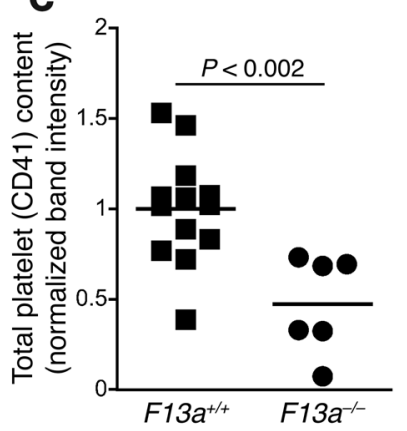

G

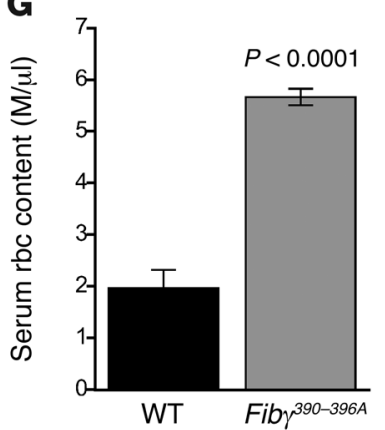

D

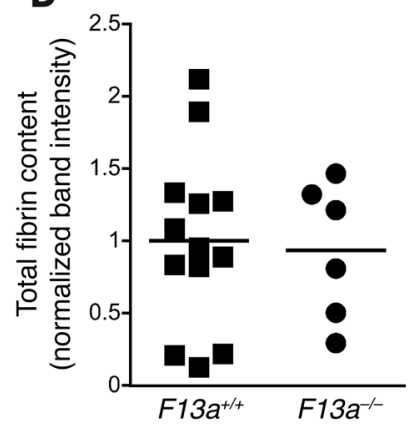

Figure 6. FXIII-deficient mice produce smaller thrombi with reduced rbc content. (A) Thrombus weights 1 day after ligation (stasis model). (B) Total neutrophil content of thrombus lysates, measured by Ly6C antigen. (C) Total platelet content of thrombus lysates, measured by CD41 antigen. (D) Total fibrin ( $\beta$-chain) antigen of thrombus lysates. (E) Total rbc content of stasis thrombus lysates, measured as hemoglobin absorbance at $575 \mathrm{~nm}$. Each dot represents an individual mouse. Lines are means. (F and $\mathbf{G})$ Serum rbc content following thrombin-initiated clot retraction of recalcified blood from (F) $F 13 a^{-/-}(n=4)$ and $(\mathbf{C})$ Fib $\gamma^{390-3964}$ mice $(n=7)$. Data represent mean \pm SEM.

actions with soluble fibrinogen and insoluble fibrin are warranted to discern the specific contributions of these residues to FXIII activation and activity.

Our data show that mutation of residues $\gamma 390-396$ delayed, but did not abolish, FXIII activation and fibrin crosslinking. The observed delay in FXIII activation and fibrin crosslinking was temporally associated with the timing of clot retraction (60-90 minutes). These findings imply the timing of fibrin formation, FXIII activation, crosslinking, and platelet-mediated clot retraction is orchestrated to promote hemostasis and that altering the timing of these events leads to the formation of abnormal clots. The major targets of FXIII(a) activity are the fibrin $\gamma$ - and $\alpha$-chains, and FXIII(a)-mediated crosslinking of these fibrin chains imparts critical structural and mechanical properties to the fibrin network. Compared with uncrosslinked fibers, crosslinked fibers are thinner and more elastic $(37,38)$ and require greater force to rupture $(39)$. Compared with uncrosslinked clots, crosslinked clots have smaller pores, increased network density, and a higher viscoelastic storage modulus (ref. 38 and reviewed in refs. 16, 40). It is currently unclear whether these effects directly mediate $\mathrm{rbc}$ retention during clot retraction. It is also possible that rbc themselves become crosslinked to the clot, either to fibrin or other clot-bound proteins or cells. FXIII has been shown to crosslink over 140 proteins in plasma (41), and the potential that FXIII(a) could crosslink proteins on the rbc surface has not been investigated. Further work to test these mechanisms is ongoing.

Thus far, genome-wide association studies have not associated FXIII SNPs with venous thrombosis. However, the most prevalent $F 13 A$ coding polymorphism (Val34Leu) has been associated with decreased risk of venous thrombosis in a subset of studies (reviewed in ref. 42). In in vitro assays, the V34L polymorphism results in faster FXIII activation and is associated with denser fibrin structure and decreased permeability in clots made with low fibrinogen, but coarser fibrin structure and increased permeability in clots made with high fibrinogen $(43,44)$. However, the role of the Val34Leu polymorphism in thrombus formation or crosslinking in vivo has not yet been determined. Together with our findings, these observations suggest a complex relationship between FXIII activation kinetics and thrombus properties.

Although the prevailing paradigm suggests that rbc are noninteracting and only incidentally present in thrombi, several lines of evidence suggest rbc actively promote clot formation and stability. Elevated levels of rbc are associated with increased risk of thrombosis in patients with polycythemia vera or patients on erythropoietin (45-47), and increasing the hematocrit decreases the bleeding time in anemic patients $\left(48^{-52}\right)$. While this effect has been attributed to rbc-mediated margination of platelets within the vessels, rbc also support thrombin generation (53-55) and suppress plasmin generation (56). Consequently, therapeutic approaches that limit thrombus rbc content may also indirectly reduce thrombus mass and stability. A recent study of experimental thrombosis showed thrombolysis is most effective in aged thrombi containing fewer intact rbc (57). These data suggest thrombus rbc content is a central determinant of thrombolytic success. Our finding that rbc retention in thrombi can be reduced by blocking FXIII activity provides a tool for investigating the specific contributions of rbc to venous thrombus formation and stability in vivo. Importantly, 
A

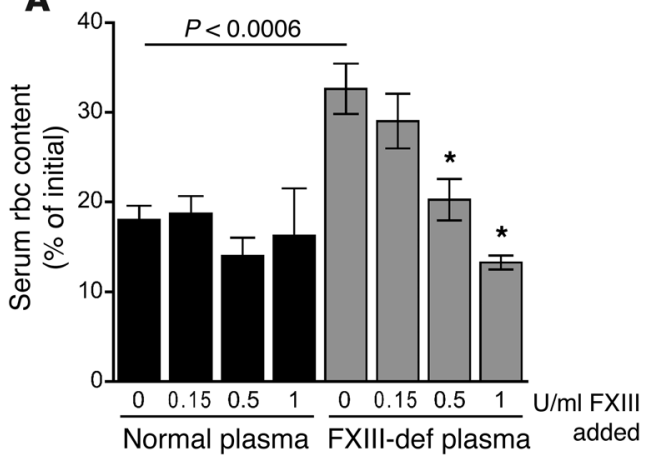

B

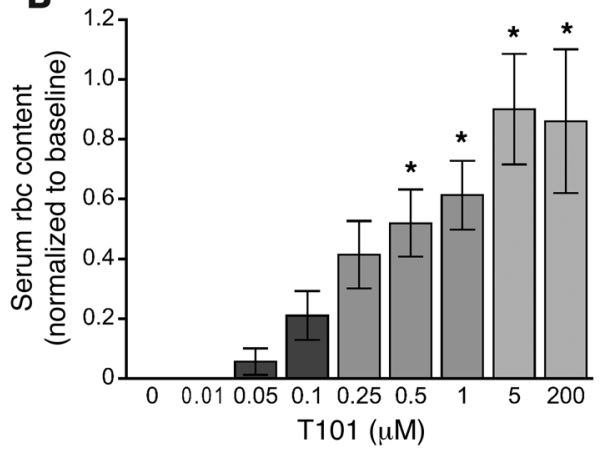

Figure 7. FXIII-deficient human clots retain fewer rbc after clot retraction, and FXIII inhibition prevents rbc retention in clots. (A) Serum rbc content following tissue factor-initiated clot retraction of human FXIII-deficient patient plasma reconstituted with washed platelets and washed rbc from normal donors and treated with increasing doses of FXIII $(0-1 \mathrm{U} / \mathrm{ml}, n=6)$. Data represent mean $\pm \mathrm{SEM}$. ${ }^{*} P<0.02$ versus FXIII-deficient plasma with no additional FXIII by ANOVA. (B) Serum rbc content following tissue factor-initiated clot retraction of normal human whole blood in the presence of the irreversible FXIIla inhibitor, T101 $(0.1-5 \mu \mathrm{M}, n=7)$. Data represent normalized mean \pm SEM. ${ }^{*} P<0.02$ versus absence of T101 by ANOVA

our findings redefine the paradigm determining venous thrombus composition and size, and identify a therapeutic target for preventing venous thrombosis.

\section{Methods}

Mice. Fib ${ }^{390-3964}$ mice (4) and $F 13 a^{-/}$mice (24) were independently backcrossed 6 generations to a $\mathrm{C} 57 \mathrm{BL} / 6 \mathrm{~J}$ background. $C D 11 b^{-/}$mice (21), also on a C57BL/6 background, were backcrossed more than 7 generations.

Murine venous thrombosis models. The IVC stasis model was performed on 8- to 10-week-old male WT, Fib ${ }^{390-396 A}, F 13 a^{-/}$, and $F 13 a^{+/+}$ mice as described $(58,59)$. Briefly, anesthetized mice were subject to sterile laparotomy and exposure of the IVC. Side branches were ligated, and lumbar branches were closed by cautery. The IVC was separated from the aorta by blunt dissection and completely ligated. The IVC stenosis model was performed as described (19). Briefly, side branches were ligated, but no lumbar branches were cauterized. Stenosis was achieved by partial ligation of the IVC using a 30-gauge needle as a temporary spacer during ligation, after which it was removed. Mice recovered with analgesia (buprenorphine, $0.05 \mathrm{mg} / \mathrm{kg}$, subcutaneous) and were maintained on acetaminophen $(6 \mathrm{mg} / \mathrm{ml})$ in their drinking water after surgery. After 24 hours, mice were anesthetized and blood drawn from the suprarenal IVC into $3.2 \%$ sodium citrate $(10 \% \mathrm{v} / \mathrm{v}$, final concentration). Blood samples were centrifuged at 5,000 $\mathrm{g}$ for 10 minutes to prepare platelet-poor plasma (PPP). Thrombi were separated from the vein wall, weighed, and frozen.

Thrombus analysis by Western blot. Frozen thrombus samples from WT, $F i b \gamma^{390-396 A}, F 13 a^{+/+}$, and $F 13 a^{-/}$mice were homogenized in lysis buffer (20 mM Tris-HCl, pH 7.5, $150 \mathrm{mM} \mathrm{NaCl}, 1 \mathrm{mM}$ EDTA, $1 \mathrm{mM}$ EGTA, 1\% Triton X-100, $2.5 \mathrm{mM}$ sodium pyrophosphate, $1 \mathrm{mM}$ $\beta$-glycerophosphate, $1 \mathrm{mM} \mathrm{Na}_{3} \mathrm{VO}_{4}$, and $1 \mathrm{mg} / \mathrm{ml} \mathrm{leupeptin}$; Cell Signaling) supplemented with $1 \mathrm{mM}$ PMSF using a Dounce Tissue Homogenizer (Bellco Glass). Thrombus lysates were kept on ice for 1 hour before centrifugation $\left(7,000 \mathrm{~g}, 15\right.$ minutes) at $4^{\circ} \mathrm{C}$. Supernatants were collected and mixed with $6 \times$ nonreducing SDS-sample buffer (Boston BioProducts). Nonreduced samples were used for blotting leukocyte (Ly6G) and platelet (CD41) antigens. For a subset of samples, the crosslinked fibrin enriched pellet was dissolved in $8 \mathrm{M}$ urea containing homa Medical Research Foundation, Oklahoma City, Oklahoma, USA) overnight at $4^{\circ} \mathrm{C}$. After washing, membranes were incubated with fluorescence-labeled secondary antibodies for 1 hour at room temperature. Membranes were then washed and scanned using an Odyssey Infrared Imaging System (LI-COR Biosciences) or GE Typhoon FLA-9000 Imager (GE Healthcare).

Thrombus rbc (hemoglobin) content. Thrombus lysates were diluted 10 -fold in $20 \mathrm{mM}$ sodium phosphate (pH 7.4) and $150 \mathrm{mM} \mathrm{NaCl}$ (PBS); absorbance was measured at $575 \mathrm{~nm}$.

Measurement of circulating TAT complexes. Postligation TAT levels of PPP prepared from IVC blood draws were measured by ELISA (Enzygnost TAT microELISA; Siemens Healthcare Diagnostics Inc.).

Measurement of plasma thrombin generation. Plasma thrombin generation was measured in 6-fold diluted plasma by calibrated automated thrombography, as described (60).

Clot retraction assays. Blood was drawn from mice into $3.2 \%$ sodium citrate $(10 \% \mathrm{v} / \mathrm{v}$, final concentration) and corn trypsin inhibitor (CTI) $(18.3 \mu \mathrm{g} / \mathrm{ml}$ final concentration). For whole-blood clot retraction, blood was used undiluted or was diluted 3-fold in HEPESbuffered saline (HBS; $20 \mathrm{mM}$ HEPES, pH 7.4, $150 \mathrm{mM} \mathrm{NaCl}$ ), in the absence or presence of the FXIII inhibitor T101 (0-200 $\mu \mathrm{M}$, final concentration; Zedira) as indicated. For PRP clot retraction, blood was centrifuged twice ( $150 \mathrm{~g}, 5$ minutes), and PRP was collected and used undiluted. Clotting was triggered in recalcified $(10 \mathrm{mM}$, final concentration) whole blood or PRP by addition of tissue factor (Innovin diluted to $1: 12,000,1 \mathrm{pM}$, final concentration) or thrombin $(2 \mathrm{U} / \mathrm{ml}$ bovine thrombin, final concentration), as indicated. In all experiments, clotting and subsequent retraction proceeded at $37^{\circ} \mathrm{C}$ for 90 minutes in siliconized glass tubes. Retracted clots were imaged to determine final percentage of retraction. Serum was collected, and rbc were measured by directly counting cells on a HV950FS Hemavet cell counter (Drew Scientific) or by diluting serum 10- to 200 -fold in HBS, measuring absorbance at $575 \mathrm{~nm}$, and comparing with a standard curve of diluted rbc enumerated with a Hemavet cell counter. To confirm that whole $\mathrm{rbc}$ were released from clots, serum was centrifuged $(100 \mathrm{~g}, 10 \mathrm{~min}-$ utes) to pellet extruded intact rbc, and the free hemoglobin content of the residual serum (absorbance at $575 \mathrm{~nm}$ ) was compared with that 
of the plasma from corresponding whole blood (prior to clot initiation and retraction) from WT and Fib $\gamma^{390-396 A}$ mice. This analysis showed less than $0.2 \%$ of total rbc hemolysis, confirming that rbc extruded from whole blood clots during clot retraction in vitro were intact. Retracted clots were also collected and weighed.

rbc washout assay in the absence of platelets. Blood was drawn from mice into $3.2 \%$ sodium citrate $(10 \% \mathrm{v} / \mathrm{v}$, final concentration) and centrifuged ( $250 \mathrm{~g}, 10$ minutes). PRP fractions were separated and processed to PFP by sequential centrifugation (2000 $g$ for 15 minutes, followed by $7000 \mathrm{~g}$ for 10 minutes). The buffy coat was removed from the rbc fraction and washed 3 times in $1.29 \mathrm{mM}$ sodium citrate, $3.33 \mathrm{mM}$ glucose, and $124 \mathrm{mM} \mathrm{NaCl}(\mathrm{pH} 7.2)$ and was centrifuged ( $250 \mathrm{~g}, 5$ minutes). rbc were resuspended in PBS with $0.1 \%$ BSA and centrifuged ( $500 \mathrm{~g}, 10$ minutes) to pack cells. Packed rbc $(4 \mu \mathrm{l})$ were added for every $100 \mu \mathrm{l}$ PFP. Flow cytometry of PFP and washed rbc revealed less than $0.01 \%$ and $10 \%$ platelet contamination (percentage of initial platelet count by GPIX-positive events) in PFP and rbc, respectively. The initial absorbance of rbc-PFP mix was determined by 50 -fold dilution in PBS. rbc-PFP mix was clotted with tissue factor (1 $\mathrm{pM}$, final concentration) and $\mathrm{CaCl}_{2}(10 \mathrm{mM}$, final concentration) at room temperature. After 1 hour, $700 \mu \mathrm{HBS}$ was added and absorbance at $575 \mathrm{~nm}$ was measured and used to calculate percentage of change from initial absorbance.

Isolation of fibrinogen from plasma with glycine precipitation. PPP was supplemented with $10 \mathrm{mM}$ PMSF and $5 \mathrm{mM}$ benzamidine (final concentration). Glycine (165 mg per ml plasma) was added, and samples were rotated at room temperature for 1 hour. The precipitate was collected via centrifugation and resuspended in HBS before reprecipitation with glycine. The precipitate was resuspended in HBS and assessed by SDS-PAGE. Samples were stored at $-80^{\circ} \mathrm{C}$.

$r b c$ adhesion assay. Microfluidic channels $(43.5 \times 500 \mu \mathrm{m}$ in crosssection) were coated with $10 \mu \mathrm{g} / \mathrm{ml} \mathrm{BSA}$, purified WT fibrinogen, or Fib ${ }^{390-396 A}$ fibrinogen for 2 hours at room temperature and then rinsed with PBS. Washed, packed rbc from WT mice were diluted 100-fold in PBS $(20,000 / \mu \mathrm{l})$, loaded into channels, and allowed to adhere for 10 minutes under static conditions. PBS was then flowed through the channels at $1000 \mathrm{~s}^{-1}$ for 5 minutes. Bright field images of the channels before and after flow were captured on an Olympus IX81 inverted light microscope with a $\times 40$ objective. Percentage of adhesion was measured by counting cells using Image J software.

Mass spectrometry-based identification of FXIII in WT fibrinogen. Purified fibrinogen was reduced and separated on a $10 \%$ Tris-glycine gel. Bands were visualized by colloidal blue silver stain (61), excised, and analyzed by the Michael Hooker University of North Carolina Proteomics Center using a MALDI TOF/TOF 4800 Mass Analyzer (ABSciex).

Detection of FXIII in murine plasma. PPP was diluted 1:120 in water and added 5:1 to reducing SDS-sample buffer. Samples were separated on a $10 \%$ Tris-glycine gel and transferred to PVDF membranes. Western blotting was performed as above, using sheep anti-FXIII-A subunit polyclonal antibody (1:1000; Enzyme Research Laboratories) and rabbit anti-FXIII-B subunit polyclonal antibody (1:1000; Sigma-Aldrich).

ELISA for FXIII binding to adherent fibrinogen. Purified mouse fibrinogen $\left(0.029 \mu \mathrm{M}\right.$ diluted in HBS containing $1 \mathrm{mM} \mathrm{CaCl}_{2}$ [HBS/ $\left.\mathrm{Ca}^{2+}\right]$ ) was coated onto a Corning 96-well high-binding microplate. Control wells were coated with $\mathrm{HBS} / \mathrm{Ca}^{2+}$ alone. Wells were blocked with $\mathrm{HBS} / \mathrm{Ca}^{2+}$ containing 0.1\% BSA and incubated with a 1:5 dilution series of Fibrogammin-P (1.95 $\mu \mathrm{M}$ to $0.2 \mathrm{pM})$. Wells were probed with sheep anti-human FXIII-A subunit antibody (1:1000) and HRP-conjugated donkey anti-sheep secondary (1:10,000; Sigma-Aldrich). All incubation steps were performed for 1 hour at room temperature and followed by washing with $\mathrm{HBS} / \mathrm{Ca}^{2+}$ containing $0.5 \%$ Tween 20. ELISAs were developed with SureBlue peroxidase substrate (KPL), and generation of blue color was monitored at $600 \mathrm{~nm}$ with a SpectraMax 340PC microplate reader. The maximum rate of substrate cleavage was determined using SoftMax software.

Plasma clot formation and detection of FXIIIa and crosslinked fibrin. PPP from WT and Fib $\gamma^{390-396 A}$ mice was recalcified (10 mM, final concentration) and clotted with tissue factor (1 pM, final concentration). At indicated time points, quenching solution (50 mM DTT, $12.5 \mathrm{mM}$ EDTA, $8 \mathrm{M}$ urea) was added. Samples were then incubated at $60^{\circ} \mathrm{C}$ for 1 hour with occasional agitation. Samples were reduced, boiled, separated on $10 \%$ Tris-glycine gels, and transferred to PVDF membranes. Membranes were probed with rabbit anti-human fibrinogen polyclonal antibodies (rabbit anti-fibrin[ogen]). Membranes were then stripped with $10 \mathrm{mM}$ DTT in $7 \mathrm{M}$ guanidine for 20 minutes at $60^{\circ} \mathrm{C}$ and reprobed with sheep anti-human FXIII-A polyclonal antibody. Band intensity (AU) was measured by densitometry using Photoshop CS6 version 13.0. Bands were normalized to initial intensity at time 0 with the following exceptions: FXIII-A* was normalized to FXIII-A at time $0, \gamma$ - $\gamma$ dimers were normalized to $\gamma$-chain at time 0 , and high MW crosslinked species were normalized to $\alpha$-chain at time 0 .

Clot retraction of reconstituted human FXIII-deficient blood. Normal and FXIII-deficient plasmas were prepared from blood drawn from consenting healthy individuals and a patient with FXIII deficiency. The patient was a 7-year-old female with severe congenital deficiency of FXIII ( $<5 \%)$ who received prophylactic FXIII concentrate infusions every 4 weeks. The blood sample was obtained before an infusion when the trough level was $14 \%$. rbc and platelets were isolated from blood drawn from consenting healthy donors into $3.2 \%$ citrate $(10 \% \mathrm{v} / \mathrm{v}$, final concentration) and CTI $(18.3 \mu \mathrm{g} / \mathrm{ml}$, final concentration) and centrifuged ( $150 \mathrm{~g}$, 20 minutes). The PRP fraction was treated with prostaglandin- $\mathrm{I}_{2}(50 \mathrm{ng} / \mathrm{ml}$, final concentration) and centrifuged $(400 \mathrm{~g}$, 20 minutes). Pelleted platelets were resuspended in Tyrode's buffer (15 mM HEPES, $3.3 \mathrm{mM} \mathrm{NaH}_{2} \mathrm{PO}_{4}$, pH 7.4, $138 \mathrm{mM} \mathrm{NaCl}$, $2.7 \mathrm{mM} \mathrm{KCl}$, $1 \mathrm{mM} \mathrm{MgCl}, 5.5 \mathrm{mM}$ dextrose), allowed to rest for 30 minutes at $37^{\circ} \mathrm{C}$, counted on a Hemavet, and diluted to 1 million/ $\mu$ l. After removing the buffy coat, the rbc fraction was washed 3 times with CGS buffer (1.29 mM sodium citrate, $3.33 \mathrm{mM}$ glucose, $124 \mathrm{mM} \mathrm{NaCl}, \mathrm{pH} 7.2$ ), centrifuged ( $400 \times g, 5$ minutes), resuspended in HBS, and packed by centrifugation $(400 \times g, 10$ minutes). Packed rbc were diluted 2 -fold in HBS and counted on a Hemavet. Plasma-derived FXIII- $\mathrm{A}_{2} \mathrm{~B}_{2}$ (Fibrogammin-P) or HBS was incubated with citrated normal and FXIII-deficient plasmas (no CTI) for 10 minutes at room temperature. Washed platelets $(100,000 / \mu \mathrm{l}$, final concentration) and $\mathrm{rbc}(4-5 \mathrm{million} / \mu \mathrm{l}$, final concentration) were combined with plasmas in siliconized wells of a 96-well plate containing tissue factor ( $1 \mathrm{pM}$, final concentration) and $\mathrm{CaCl}_{2}$ (10 mM, final concentration). Clot formation and retraction were allowed to proceed for 90 minutes at $37^{\circ} \mathrm{C}$. rbc content of serum was measured by absorbance as described above.

Statistics. Descriptive statistics (mean, median, SD, SEM) were calculated for each condition, and Lilliefors test was used to assess normality. Data were compared by Student's $t$ test with equal or unequal variance, as appropriate, for experiments with 2 groups. ANOVA was 
used for experiments with more than 2 conditions, with Bonferroni or Dunnet post hoc tests for between-group comparisons. $P<0.05$ was considered significant.

Study approval. All animal procedures were approved by the University of North Carolina and Cincinnati Children's Hospital Institutional Animal Care and Use Committees. All procedures with human blood were approved by the University of North Carolina and University of Colorado Institutional Review Boards. Written informed consent was received from all study participants.

\section{Acknowledgments}

We thank Katie McElhinney, Heyman I. Peraza Magana, Christa I. DeVette, and Lori A. Holle for excellent technical assistance,
Maureane Hoffman, Leslie Parise, Robert A. Campbell, and Dougald M. Monroe for thoughtful suggestions, and the University of North Carolina Michael Hooker Proteomics Core Facility for mass spectrometry analysis. This study was supported by funding from the NIH (R01HL094740 to A.S. Wolberg; F31HL112608 to M.M. Aleman) and the American Heart Association (12GRNT11840006 to A.S. Wolberg).

Address correspondence to: Alisa S. Wolberg, Department of Pathology and Laboratory Medicine, University of North Carolina at Chapel Hill, 815 Brinkhous-Bullitt Building, CB \#7525, Chapel Hill, North Carolina 27599-7525, USA. Phone: 919.966.8430; E-mail: alisa_wolberg@med.unc.edu.
1. Mackman N. Triggers, targets and treatments for thrombosis. Nature. 2008;451(7181):914-918.

2. Liu W, et al. Fibrin fibers have extraordinary extensibility and elasticity. Science. 2006 313(5787):634.

3. Mosesson MW, Siebenlist KR, Meh DA. The structure and biological features of fibrinogen and fibrin. Ann N Y Acad Sci. 2001;936:11-30.

4. Flick MJ, et al. Leukocyte engagement of fibrin(ogen) via the integrin receptor $\alpha \mathrm{M} \beta 2$ / $\mathrm{Mac}-1$ is critical for host inflammatory response in vivo. J Clin Invest. 2004;113(11):1596-1606.

5. Adams RA, et al. The fibrin-derived $\gamma 377-395$ peptide inhibits microglia activation and suppresses relapsing paralysis in central nervous system autoimmune disease. J Exp Med. 2007;204(3):571-582.

6. Davalos D, et al. Fibrinogen-induced perivascular microglial clustering is required for the development of axonal damage in neuroinflammation. Nat Commun. 2012;3:1227.

7. Flick MJ, et al. Fibrin(ogen) exacerbates inflammatory joint disease through a mechanism linked to the integrin $\alpha \mathrm{M} \beta 2$ binding motif. J Clin Invest. 2007;117(11):3224-3235.

8. Steinbrecher KA, et al. Colitis-associated cancer is dependent on the interplay between the hemostatic and inflammatory systems and supported by integrin $\alpha \mathrm{M} \beta 2$ engagement of fibrinogen. Cancer Res. 2010;70(7):2634-2643.

9. Vidal B, et al. Amelioration of Duchenne muscular dystrophy in mdx mice by elimination of matrix-associated fibrin-driven inflammation coupled to the $\alpha \mathrm{M} \beta 2$ leukocyte integrin receptor. Hum Mol Genet. 2012;21(9):1989-2004.

10. Takagi T, Doolittle RF. Amino acid sequence studies on factor XIII and the peptide released during its activation by thrombin. Biochemistry. 1974;13(4):750-756.

11. Schroeder V, Vuissoz JM, Caflisch A, Kohler HP. Factor XIII activation peptide is released into plasma upon cleavage by thrombin and shows a different structure compared to its bound form. Thromb Haemost. 2007;97(6):890-898.

12. Lorand L, et al. Dissociation of the subunit structure of fibrin stabilizing factor during activation of the zymogen. Biochem Biophys Res Commun. 1974;56(4):914-922.

13. Curtis CG, et al. Calcium-dependent unmasking of active center cysteine during activation of fibrin stabilizing factor. Biochemistry. 1974; 13(18):3774-3780.

14. Hornyak TJ, Shafer JA. Role of calcium ion in the generation of factor XIII activity. Biochemistry. 1991;30(25):6175-6182.

15. Greenberg CS, Shuman MA. The zymogen forms of blood coagulation factor XIII bind specifically to fibrinogen. J Biol Chem. 1982;257(11):6096-6101.

16. Karimi M, Bereczky Z, Cohan N, Muszbek L. Factor XIII deficiency. Semin Thromb Hemost. 2009;35(4):426-438.

17. Varma MR, et al. Neutropenia impairs venous thrombosis resolution in the rat. J Vasc Surg. 2003;38(5):1090-1098.

18. Day SM, et al. Macrovascular thrombosis is driven by tissue factor derived primarily from the blood vessel wall. Blood. 2005;105(1):192-198.

19. Brill A, et al. von Willebrand factor-mediated platelet adhesion is critical for deep vein thrombosis in mouse models. Blood. 2011;117(4):1400-1407.

20. von Bruhl ML, et al. Monocytes, neutrophils, and platelets cooperate to initiate and propagate venous thrombosis in mice in vivo. J Exp Med. 2012;209(4):819-835.

21. Lu H, et al. LFA-1 is sufficient in mediating neutrophil emigration in Mac-1-deficient mice. JClin Invest. 1997;99(6):1340-1350.

22. Hermand P, et al. Red cell ICAM-4 is a novel ligand for platelet-activated $\alpha \operatorname{IIb} \beta 3$ integrin. J Biol Chem. 2003;278(7):4892-4898.

23. Goel MS, Diamond SL. Adhesion of normal erythrocytes at depressed venous shear rates to activated neutrophils, activated platelets, and fibrin polymerized from plasma. Blood. 2002; 100(10):3797-3803.

24. Souri M, Koseki-Kuno S, Takeda N, Degen JL, Ichinose A. Administration of factor XIII B subunit increased plasma factor XIII A subunit levels in factor XIII B subunit knock-out mice. Int J Hematol. 2008;87(1):60-68.

25. Hanna M. Congenital deficiency of factor 13: report of a family from Newfoundland with associated mild deficiency of factor XII. Pediatrics. 1970;46(4):611-619.

26. Heit JA. Venous thromboembolism epidemiology: implications for prevention and management. Semin Thromb Hemost. 2002;28(suppl 2):3-13.

27. Go AS, et al. Heart disease and stroke statistics 2013 update: a report from the American Heart Association. Circulation. 2013;127(1):e6-e245.
28. Hull RD, Marder VJ, Mah AF, Biel RK, Brant RF. Quantitative assessment of thrombus burden predicts the outcome of treatment for venous thrombosis: a systematic review. Am JMed. 2005; 118(5):456-464.

29. Cines DB, et al. Clot contraction: compression of erythrocytes into tightly packed polyhedra and redistribution of platelets and fibrin. Blood. 2014;123(10):1596-1603

30. Leidy EM, Stern AM, Friedman PA, Bush LR. Enhanced thrombolysis by a factor XIIIa inhibitor in a rabbit model of femoral artery thrombosis. Thromb Res. 1990;59(1):15-26.

31. Shebuski RJ, Sitko GR, Claremon DA, Baldwin JJ, Remy DC, Stern AM. Inhibition of factor XIIIa in a canine model of coronary thrombosis: effect on reperfusion and acute reocclusion after recombinant tissue-type plasminogen activator. Blood. 1990;75(7):1455-1459.

32. Levy JH, Greenberg C. Biology of Factor XIII and clinical manifestations of Factor XIII deficiency. Transfusion. 2013;53(5):1120-1131.

33. Lawrie AS, Green L, Mackie IJ, Liesner R, Machin SJ, Peyvandi F. Factor XIII - an under diagnosed deficiency - are we using the right assays? J Thromb Haemost. 2010;8(11):2478-2482.

34. Smith KA, et al. Interactions between factor $\mathrm{XIII}$ and the alphaC region of fibrinogen. Blood. 2011;117(12):3460-3468.

35. Siebenlist KR, Meh DA, Mosesson MW. Plasma factor XIII binds specifically to fibrinogen molecules containing gamma chains. Biochemistry. 1996;35(32):10448-10453.

36. Gersh KC, Lord ST. An investigation of Factor XIII binding to recombinant $\gamma^{\prime} / \gamma^{\prime}$ and $\gamma / \gamma^{\prime}$ fibrinogen. Blood. 2006;108:485a.

37. Collet JP, Shuman H, Ledger RE, Lee S, Weisel JW. The elasticity of an individual fibrin fiber in a clot. Proc Natl Acad Sci U S A. 2005;102(26):9133-9137.

38. Hethershaw EL, et al. The effect of blood coagulation factor XIII on fibrin clot structure and fibrinolysis. J Thromb Haemost. 2014;12(2):197-205.

39. Helms CC, Ariens RA, Uitte de Willige S, Standeven KF, Guthold M. $\alpha$ - $\alpha$ Cross-links increase fibrin fiber elasticity and stiffness. Biophys J. 2012;102(1):168-175.

40. Lorand L. Factor XIII: structure, activation, and interactions with fibrinogen and fibrin. Ann NY Acad Sci. 2001;936:291-311.

41. Nikolajsen CL, Dyrlund TF, Toftgaard Poulsen 
E, Enghild JJ, Scavenius C. Coagulation Factor XIIIa substrates in human plasma. identification and incorporation into the clot. J Biol Chem. 2014;289(10):6526-6534.

42. Bereczky Z, Muszbek L. Factor XIII and venous thromboembolism. Semin Thromb Hemost. 2011; 37(3):305-314.

43. Ariens RA, Philippou H, Nagaswami C, Weisel JW, Lane DA, Grant PJ. The factor XIII V34L polymorphism accelerates thrombin activation of factor XIII and affects cross-linked fibrin structure. Blood. 2000;96(3):988-995.

44. Lim BC, Ariens RA, Carter AM, Weisel JW, Grant PJ. Genetic regulation of fibrin structure and function: complex gene-environment interactions may modulate vascular risk. Lancet. 2003; 361(9367):1424-1431.

45. Andrews DA, Low PS. Role of red blood cells in thrombosis. Curr Opin Hematol. 1999;6(2):76-82.

46. Dicato M. Venous thromboembolic events and erythropoiesis-stimulating agents: an update. Oncologist. 2008;13(suppl 3):11-15.

47. Spivak JL. Polycythemia vera: myths, mechanisms, and management. Blood. 2002; 100(13):4272-4290.
48. Small M, Lowe GD, Forbes CD, Thomson JA. Thromboembolic complications in Cushing's syndrome. Clin Endocrinol (Oxf). 1983;19(4):503-511.

49. Valeri CR, et al. Anemia-induced increase in the bleeding time: implications for treatment of nonsurgical blood loss. Transfusion. 2001;41(8):977-983.

50. Blajchman MA, Bordin JO, Bardossy L, Heddle NM. The contribution of the haematocrit to thrombocytopenic bleeding in experimental animals. Br J Haematol. 1994;86(2):347-350.

51. Ho CH. The hemostatic effect of packed red cell transfusion in patients with anemia. Transfusion. 1998;38(11-12):1011-1014.

52. Ho CH. Increase of red blood cells can shorten the bleeding time in patients with iron deficiency anemia. Blood.1998;91(3):1094.

53. Peyrou V, Lormeau JC, Herault JP, Gaich C, Pfliegger AM, Herbert JM. Contribution of erythrocytes to thrombin generation in whole blood. Thromb Haemost. 1999;81(3):400-406.

54. Horne MK, Horne MK 3rd, Cullinane AM, Merryman PK, Hoddeson EK. The effect of red blood cells on thrombin generation. Br J Haematol. 2006;133(4):403-408.

55. Whelihan MF, Zachary V, Orfeo T, Mann KG.
Prothrombin activation in blood coagulation: the erythrocyte contribution to thrombin generation. Blood. 2012;120(18):3837-3845.

56. Wohner N, et al. Lytic resistance of fibrin containing red blood cells. Arterioscler Thromb Vasc Biol. 2011;31(10):2306-2313.

57. Saha P, et al. Magnetic resonance T1 relaxation time of venous thrombus is determined by iron processing and predicts susceptibility to lysis. Circulation. 2013;128(7):729-736.

58. Henke PK, et al. Deep vein thrombosis resolution is modulated by monocyte CXCR2-mediated activity in a mouse model. Arterioscler Thromb Vasc Biol. 2004;24(6):1130-1137.

59. Aleman MM, et al. Elevated prothrombin promotes venous, but not arterial, thrombosis in mice. Arterioscler Thromb Vasc Biol. 2013;33(8):1829-1836.

60. Dargaud Y, Spronk HM, Leenders P, Hemker HC, Ten Cate H. Monitoring platelet dependent thrombin generation in mice. Thromb Res. 2010;126(5):436-441.

61. Candiano G, et al. Blue silver: a very sensitive colloidal Coomassie G-250 staining for proteome analysis. Electrophoresis. 2004;25(9):1327-1333. 